\title{
Effects of Pulse Current on an Aluminum Powder Oxide Layer During Pulse Current Pressure Sintering *1
}

\author{
Takekazu Nagae ${ }^{1}$, Masaru Yokota $^{2}$, Masateru Nose $^{2}$, Shogo Tomida ${ }^{1}$, \\ Takashi Kamiya $^{3, * 2}$ and Shigeoki Saji ${ }^{3}$ \\ ${ }^{1}$ Central Research Institute, Toyama Industrial Technology Center, Takaoka 933-0981, Japan \\ ${ }^{2}$ Takaoka National College, Takaoka 933-8588, Japan \\ ${ }^{3}$ Faculty of Engineering, Toyama University, Toyama 930-8555, Japan
}

\begin{abstract}
The pulse current pressure sintering and hot press process were applied for sintering of aluminum powder produced by water and gas atomizing methods. The pulse current pressure sintering process could densify the water atomized powder in a short time compared with the hot pressing because it could remove the $\mathrm{H}_{2}$ gas at lower temperature. The gas prevents sintering of aluminium powder. The tensile strength of the pulse current pressure sintered gas atomized powder which contains low $\mathrm{H}_{2}$ was higher than that of hot pressed specimen. The electric resistivity of sintered specimens obtained by pulse current pressure sintering process was lower than that of hot pressed specimen. The oxide layer destruction was confirmed by this measurement of electric resistivity. The oxide layers were supposed to be fractured by the high temperature region which is attributed to Joule heat by contact resistance.
\end{abstract}

(Received March 4, 2002; Accepted April 26, 2002)

Keywords: pulse current pressure sintering, hot press, aluminum powder, oxide layer, hydrogen content, oxygen content, contact resistance

\section{Introduction}

Recently, Pulse Current Pressure (PCP) sintering, which is commercially called Spark Plasma Sintering (SPS) or Plasma Activated Sintering (PAS), is expected to be a new process for sintering various kinds of materials. This system is a kind of solid compression sintering process which employs a low voltage $(\sim 12 \mathrm{~V})$ and a high density pulsed electric current $\left(\sim 10^{7} \mathrm{Am}^{-2}\right)$ under uni-axial pressure. Sintering is carried out at lower temperatures with a shorter period than conventional sintering processes, so the PCP process is applied for sintering, ${ }^{1-3)}$ joining ${ }^{4)}$ and surface modification ${ }^{5)}$ of various kinds of materials which need to suppress grain growth, diffusion and crystallization. ${ }^{6}$ )

A variety of research ${ }^{7-17)}$ has been done to reveal the sintering mechanism of the PCP sintering process such as microstructure observation ${ }^{7)}$ and resistivity measurement. ${ }^{8)}$ The heating mechanism was examined by measurement of the electric current ${ }^{14)}$ and temperature measurement of the sample powder during sintering. ${ }^{9-13)}$ Other research studied the rate of densification to evaluate the sintering mechanism. $\left.{ }^{9}, 15,16\right)$ However, it is still unclear whether discharge between particles occurs and Joule heat generation occurs locally. ${ }^{6)}$

Nanko ${ }^{9)}$ et al. compared the densification processes between the PCP sintering process and the conventional hot press (HP) method using cast iron powder. They observed that the rate of densification of the cast iron powder for the PCP process was almost the same as that of the HP process, and the neck between the particles did not melt. However, because $\mathrm{Al}$ and Ti powder have a strong oxide layer, they did

${ }^{* 1}$ This Paper was Originally Published in Japanese in J. Japan Inst. Metals, 65 (2001) 726-733.

${ }^{*}$ Graduate Student, Toyama University. Present address: Soode Nagano CO. LTD not deny the assumption of Matsugi ${ }^{8)}$ et al. that discharge between the particles occurs, and Joule heating at the contact region between the particles break up the oxide layer which enhances the neck growth.

Nishimoto et al. ${ }^{15)}$ compared the densification rate of oxide dispersion strengthened alloys for the PCP sintering process with HP and a direct electric current sintering (DECS) process. They showed the densification rate of the PCP process at the diffusion-creep controlled stage was larger than that of HP and DECS. They assumed this result was due to the high temperature region at the interface of the particles. Nose et al. ${ }^{17)}$ sintered a mechanical alloyed $2 \mathrm{Nb} / \mathrm{Al}$ powder by the PCP process and an electric furnace. Comparing the synthesized phase of sintered compacts between these processes, they qualitatively explained the generation of a high temperature region at the contacting points of the particles.

Thus, the proposed sintering mechanisms of the PCP process by several researchers have not been agreed to, but the effectiveness of pulsed current was partially agreed to for PCP sintering on hard sinterable alloys such as Al alloy or intermetallic compounds. ${ }^{7}{ }^{15-17)}$ In order to elucidate the effect of pulsed current, the different of heating mechanisms and oxide behaviors at the interface of the particles between the PCP and the HP process should be clarified. Under the status quo, neither the observation of breaking up the oxide layer, nor quantifiable evaluation of Joule heat at the interface of the particles has been carried out.

In this study, Al powder was sintered by two kinds of solid compression sintering processes; the PCP and the HP sintering processes. The differences of the microstructures and the mechanical properties between these methods were evaluated. Al powder is a hard sinterable material because of both the existence of an oxide layer on its surface, and the additional oxide layer generated by the reaction among $\mathrm{Al}$, adsorbed water, and hydroxide. ${ }^{18)}$ Mechanical properties of a 
sintered compact are affected by the reaction during heating. Sintered water atomized $\mathrm{Al}$ powder, contains a large amount of adsorbed gases to clarify the reactions on the powder surface during the PCP sintering process. Argon gas atomized powder, which has a clean surface, was sintered and the heat generation at the contact point of the $\mathrm{Al}$ particles was evaluated quantitatively.

\section{Experimental Procedure}

The starting materials were water and gas atomized $\mathrm{Al}$ powder. SEM micrographs of the starting powder are shown in Fig. 1. The water atomized powder shows an irregular shape, and the gas atomized powder shows a sphere shape. Table 1 shows the purity, hydrogen content, oxygen content, and the mean particle size of the starting powder.

Pulsed current pressure sintering apparatus (Sumitomo coal mining: SPS-1050) and conventional hot press sintering apparatus (Tokyo shinku) were used for sintering the $\mathrm{Al}$ powder. Figure 2 shows a schematic diagram of the PCP sintering apparatus. A sample powder poured into the conductive mold is pressed by the water cooled electrodes and heated to
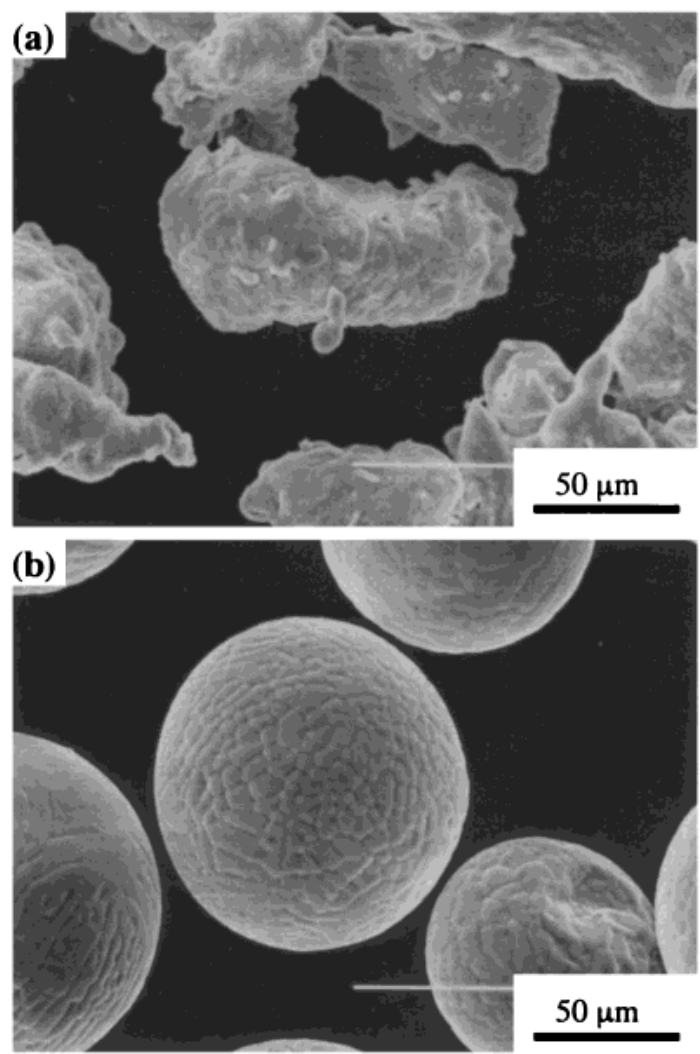

Fig. 1 Shapes of aluminum powders used. (a) water atomized powder (irregular shape). (b) gas atomized powder (sphere shape).

Table 1 Aluminum powder characteristics.

\begin{tabular}{cccccc}
\hline Powder & Purity & $\begin{array}{c}\text { Hydrogen } \\
\text { content } \\
(\mathrm{mpm})\end{array}$ & $\begin{array}{c}\text { Oxygen } \\
\text { content } \\
(\mathrm{ppm})\end{array}$ & $\begin{array}{c}\text { Particle } \\
\text { size } \\
d / \mu \mathrm{m}\end{array}$ & $\begin{array}{c}\text { Manufactured } \\
\text { method }\end{array}$ \\
\hline (a) & 99.7 & 230 & 1970 & $100-150$ & water atomized \\
(b) & 99.7 & 30 & 110 & $100-120$ & gas atomized \\
\hline
\end{tabular}

sinter by a pulsed current. An HP apparatus is a kind of uniaxial compressive sintering method which employs a graphite heater to heat the sample powder. Table 2 shows the sintering schedule in this experiment. Although rapid heating $\left(1.5 \sim 3 \mathrm{Ks}^{-1}\right)$ is one of the unique characteristics of the PCP sintering process, a low heating rate of $0.3 \mathrm{Ks}^{-1}$ was used to confirm the HP process. The temperature of the powder is different from that of the mold during sintering. The sintering temperature was corrected by preliminary experiments. The holding period means the lapsed time while setting the temperature. Powder was pressed at $28 \mathrm{MPa}$ during the heat up period. The sintering pressure shown in Table 2 was loaded when the temperature reachead the holding temperature.

The density of the sintered specimen was measured using the Archimedes principle. The hydrogen and oxide content were analyzed by the thermal conductivity method and the infrared absorption method, respectively. The electric resistivity was measured by the four-point probe method. Microstructures were examined by an optical microscope (OM) and a scanning electron microscope (SEM). The oxide layer was observed by a transmission electron microscope (TEM). The specimens for the tensile tests were cut using a wire electric discharge machine out of sintered compacts. Tensile tests were performed using a screw-driven testing machine at room temperature.

\section{Results and Discussion}

\subsection{Sintering of water atomized Al powder}

Figure 3 shows the changes in the density of the water atomized $\mathrm{Al}$ powder compact sintered by the PCP sintering and the conventional HP sintering processes. The density of the specimen sintered at $773 \mathrm{~K}$ by the PCP sintering

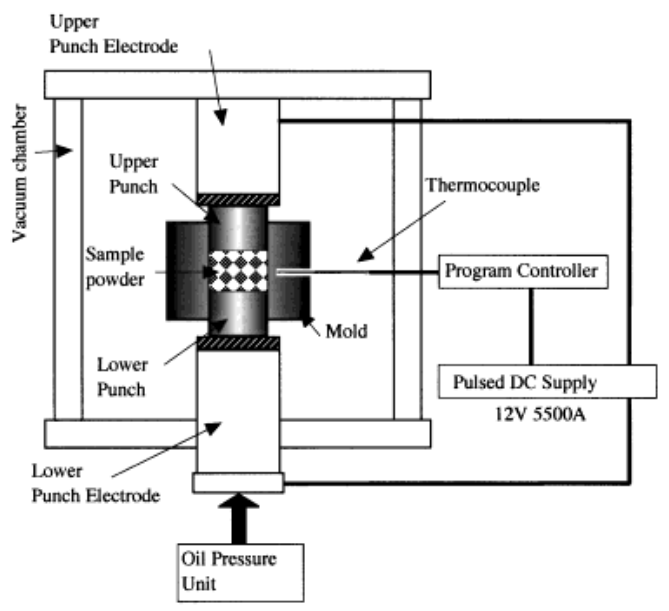

Fig. 2 Schematic diagram of the pulse current pressure sintering apparatus.

Table 2 Experimental conditions for sintering process by the pulse current pressure sintering and the hot press method.

\begin{tabular}{|c|c|c|c|c|}
\hline Powder & $\begin{array}{l}\text { Heating rate } \\
\qquad\left(\mathrm{K} \cdot \mathrm{s}^{-1}\right)\end{array}$ & $\begin{array}{c}\text { Sintering } \\
\text { temperature } \\
T / \mathrm{K}\end{array}$ & $\begin{array}{l}\text { Holding period } \\
\qquad t / \mathrm{s}\end{array}$ & $\begin{array}{l}\text { Pressure } \\
p / \mathrm{MPa}\end{array}$ \\
\hline (a) & 0.3 & 773,873 & $300,600,1800,3600$ & $40 \mathrm{MPa}$ \\
\hline (b) & 0.3 & 813,873 & $300,600,1800,3600$ & $40 \mathrm{MPa}$ \\
\hline
\end{tabular}




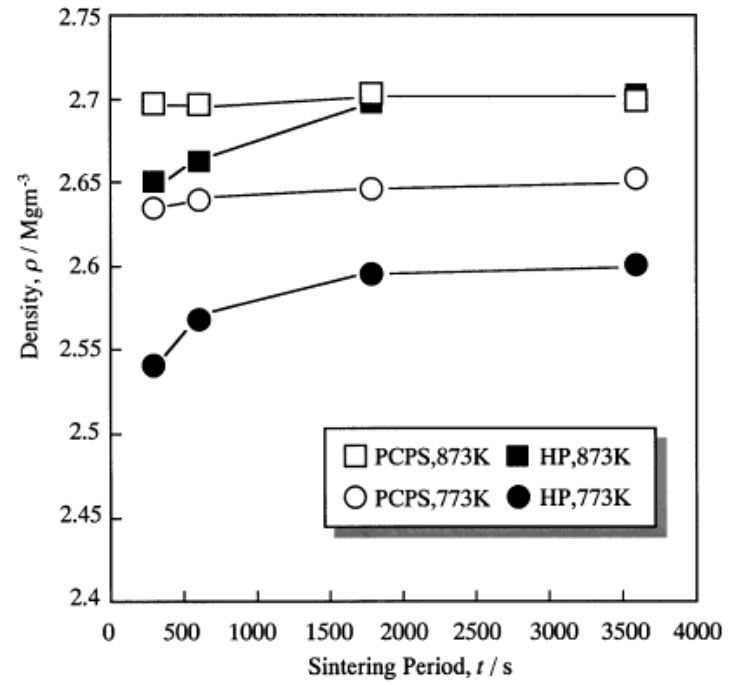

Fig. 3 Changes in density of the sintered compact by pulse current pressure sintering and the hot press method.

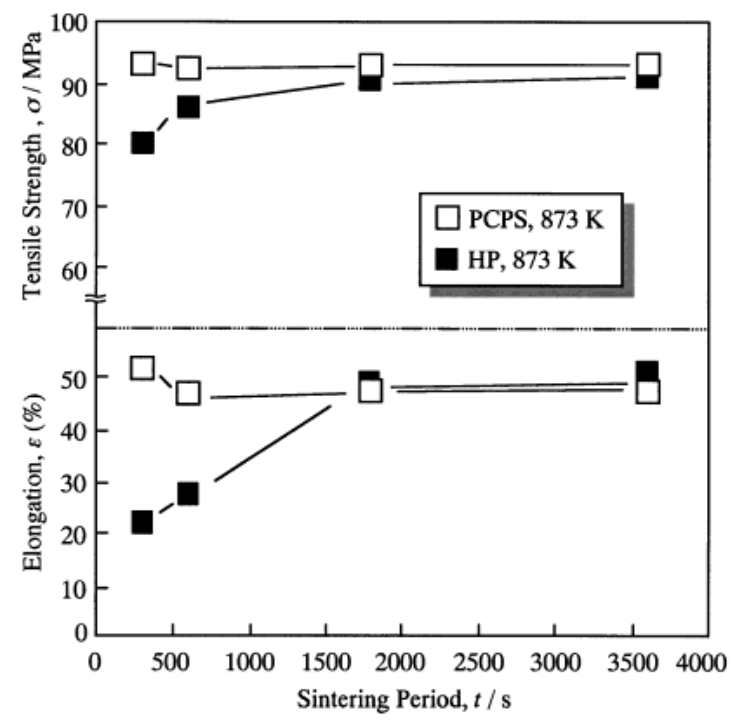

Fig. 4 Mechanical properties of the specimen vs. sintered period sintered by the pulse current pressure sintering and the hot press method.

method was higher than that of the HP specimen, but it did not reach the value of the theoretical density of pure $\mathrm{Al},{ }^{19)}$ which is $2.7 \mathrm{Mgm}^{-3}$ after a $3600 \mathrm{~s}$ holding period. When the powder was sintered at $873 \mathrm{~K}$, the density reached was about $2.7 \mathrm{Mgm}^{-3}$ after a $300 \mathrm{~s}$ sintering period by the PCP sintering method. In case of the HP specimen, the value reached $2.7 \mathrm{Mgm}^{-3}$ after $1200 \mathrm{~s}$ holding period. The PCP sintering method densified the water atomized $\mathrm{Al}$ powder for the shorter sintering period. Figure 4 shows the tensile strength and the elongation of the compact sintered at $873 \mathrm{~K}$. The tensile strength and the elongation of the compact sintered by the PCP sintering process reached about $90 \mathrm{MPa}$ and $50 \%$, respectively within $300 \mathrm{~s}$. The value of the HP specimen reached almost the same as the specimen by the PCP sintering process after an $1800 \mathrm{~s}$ sintering period.

On the $\mathrm{Al}$ powder surface, $\mathrm{H}_{2}$ gas is generated by reactions among $\mathrm{Al}$ oxide, hydroxide and metal as described below. ${ }^{18)}$

$\mathrm{Al}_{2} \mathrm{O}_{3} \cdot 3 \mathrm{H}_{2} \mathrm{O} \rightarrow \mathrm{Al}_{2} \mathrm{O}_{3} \cdot \mathrm{H}_{2} \mathrm{O}+2 \mathrm{H}_{2} \mathrm{O} \uparrow(420 \sim 770 \mathrm{~K})$

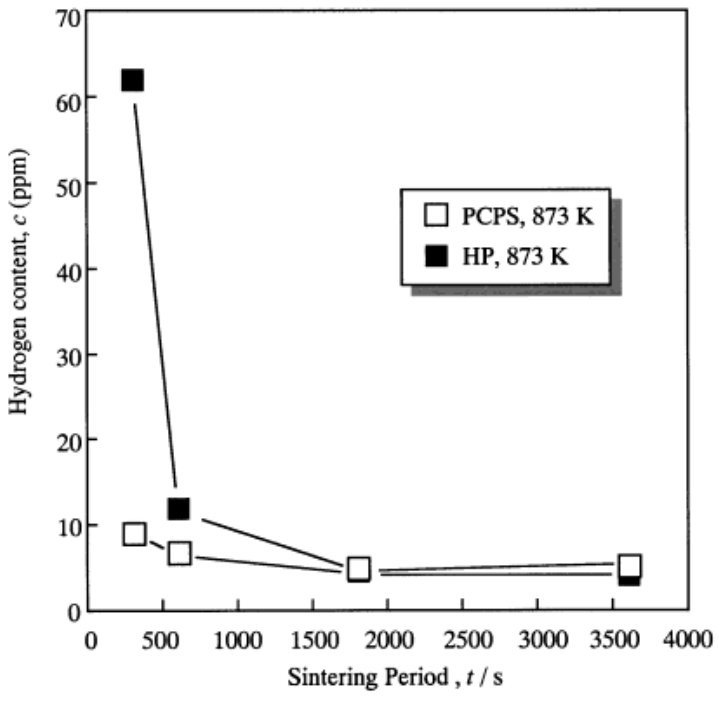

Fig. 5 Hydrogen content of Al compact sintered by the pulse current pressure sintering and the hot pressing method.

$$
2 \mathrm{Al}+3 \mathrm{H}_{2} \mathrm{O} \rightarrow \mathrm{Al}_{2} \mathrm{O}_{3}+\mathrm{H}_{2} \uparrow(620 \mathrm{~K} \sim)
$$

At temperatures above $420 \mathrm{~K}$, the hydroxide is decomposed. When the out gassed water vapor is trapped in the sintered compact, densification of the $\mathrm{Al}$ powder is inhibited by the $\mathrm{Al}$ oxide and $\mathrm{H}_{2}$ gas generated by the reaction with the trapped water vapor. Figure 5 shows changes in the hydrogen content in the sintered specimen with the sintering period. The hydrogen content of the specimens sintered by the PCP and the $\mathrm{HP}$ sintering processes for $300 \mathrm{~s}$ were less than $10 \mathrm{ppm}$ and more than $60 \mathrm{ppm}$, respectively. The hydrogen content in the HP specimen decreased as the sintering period increased because of the diffusion of hydrogen. The value of the HP specimen reached that of the PCP sintering process after a sintering period of $1800 \mathrm{~s}$. The oxygen content of the specimens sintered by the PCP and HP sintering processes were $1 \%$ mass and $0.5 \%$ mass, respectively. These values were largely unaffected by the sintering period. Oxide was generated more in the PCP sintered compact than the HP compacts. This result can be reasoned by the assumption ${ }^{8,15,17)}$ of a high temperature region at the contact points of the $\mathrm{Al}$ particles. When the reaction of the decomposition of hydroxide begins at $420 \mathrm{~K}$, the Al powder compact has many open pores. Water vapor can be out gassed from the specimen. When the sintering temperature reached $620 \mathrm{~K}$ (starting temp. of reaction (2)), the amount of water vapor decreased in the HP sintering process. In the case of the PCP sintering process, oxide and hydrogen were generated at the high temperature region at the contact points of the $\mathrm{Al}$ particles, so that the amount of oxygen was supposed to be larger than that of the HP sintered compact.

A higher content of oxygen seems to decline the tensile strength and elongation of the sintered compact, but does not affect the mechanical properties. As shown in the TEM photo of the interface of the Al particles in the PCP sintered compact (Fig. 6), the oxide layer on the Al powder was broken into a granular shape. The shape of the starting material of the water atomized $\mathrm{Al}$ powder particles were irregular as shown in Fig. 1, so the oxide layer was broken because of the shear deformation during sintering. High mechanical properties were achieved due to the breakdown of the oxide layer. 


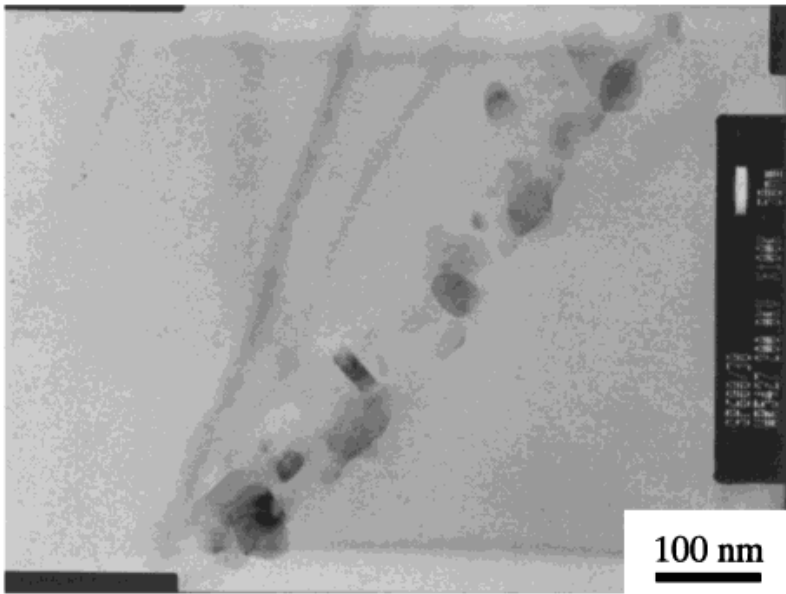

Fig. 6 The oxide layer of the specimen between $\mathrm{Al}$ particles sintered by the pulse current pressure sintering method at $873 \mathrm{~K}$ for $1.8 \mathrm{ks}$ under a load of $40 \mathrm{MPa}$.

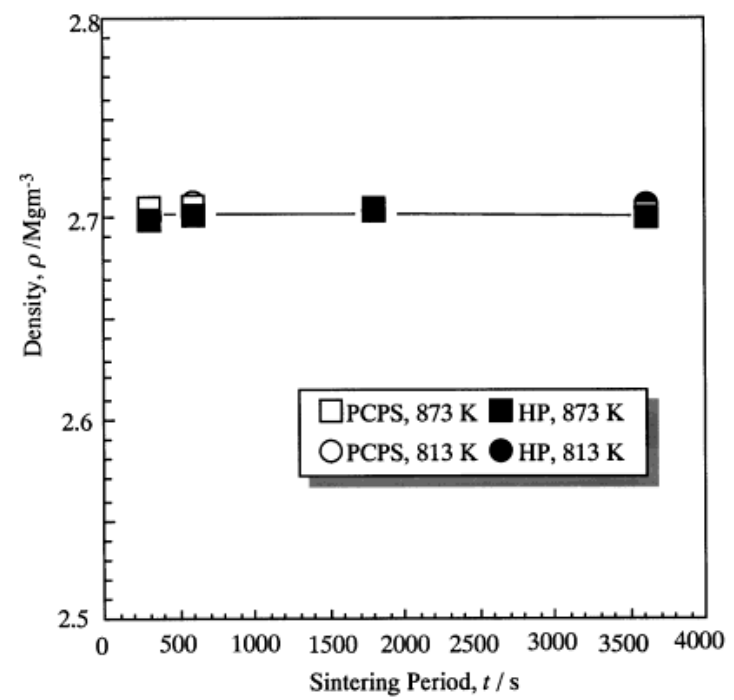

Fig. 7 Changes in density of sintered gas atomized Al powder compact by the pulse current pressure sintering and the hot pressing method.

\subsection{Sintering of gas atomized Al powder}

As shown in Fig. 7, the density of the sintered compact by both the PCP and the HP sintering processes reached about $2.7 \mathrm{Mgm}^{-3}$ at a $300 \mathrm{~s}$ holding period. Compared to the water atomized powder, densification progressed at a shorter sintering period. One of the reasons is that the gas atomized powder has a clean surface with a low amount of adsorbed gas which inhibits the densification. The other reason is that a high solids filling ratio was achieved by compressive force because of the sphere shape of the powder. ${ }^{20)}$ Figure 8 shows the tensile strength and elongation of the gas atomized Al powder compacts sintered by the PCP and HP processes. The mechanical properties of the PCP sintered compact were in excess of those of the HP compact at almost all sintering conditions. Since the sintered density was almost equal between both methods, the difference of mechanical properties was caused by difference of joint strength of each of the Al particles. Fractuatred surfaces after the tensile test are shown in Fig. 9. The dimple pattern was not observed at the fractured surface of the HP sintered specimen, but was observed at the PCP sintered compact. This means that the joint between the

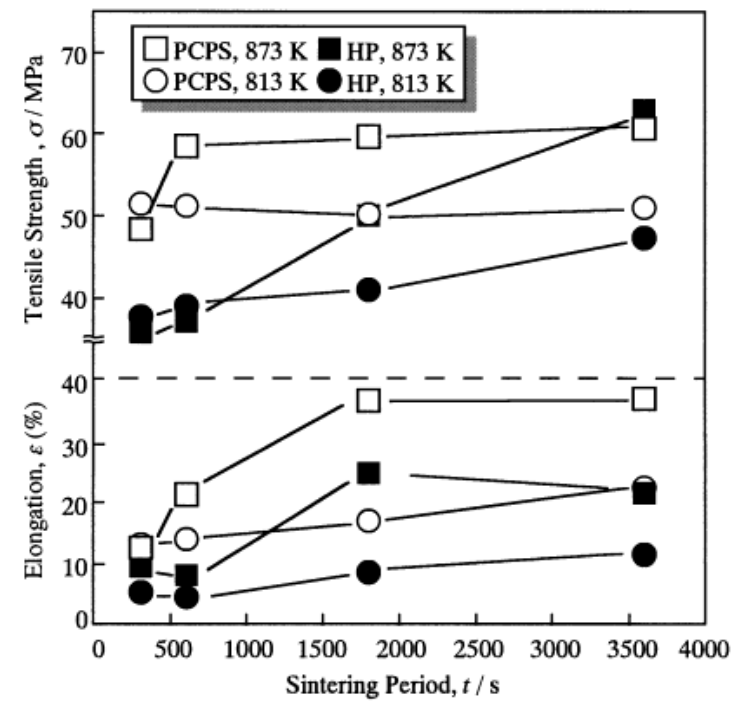

Fig. 8 Tensile strength and mechanical properties of sintered gas atomized Al powder.

Al particles in the PCP sintered compact was stronger than that of the HP sintered one. The metal bonded region between the $\mathrm{Al}$ particles is supposed to be increased by the breakup of the oxide layer during the PCP sintering process. Figure 10 shows the oxide layer of gas atomized $\mathrm{Al}$ powder compacts sintered at $813 \mathrm{~K}$ for $600 \mathrm{~s}$ by the HP and PCP sintering processes. Both of the oxide layers showed a film shape while the oxide layer in the water atomized powder compact showed a granular shape as shown in Fig. 6. The tensile strength of the gas atomized compact was lower than that of the water atomized powder compact because the oxide layer in the water atomized compact was broken up with more force than that of the gas atomized powder compact. The oxide layer in the HP compact had some cracks, but was not segmentised. In Photo (b), segments of the oxide layer can be observed. Oxide layer segmentation affects the electric resistivity of a sintered compact. Figure 11 shows electric resistivity plotted against the sintering period. The electric resistivity of the PCP compact sintered for $300 \mathrm{~s}$ was $3.1 \times 10^{-6} \Omega \mathrm{m}$, and it decreased a little when the sintering period become longer. This value of the HP compact sintered for $300 \mathrm{~s}$ was higher $0.2 \sim 0.3 \times 10^{-6} \Omega \cdot \mathrm{m}$ than that of the PCP compact. In the case of the HP compact sintered at $873 \mathrm{~K}, 3600$ s (12 times longer than PCP compact) was needed to produce the same resistivity as the PCP compact. This means that the PCP sintering process can effectively break up the oxide layer in a short period.

\subsection{Discussion of the heating mechanism}

Since the PCP sintered compact was densified in a shorter period and had larger tensile strength than that of the HP process carried out in the same sintering conditions, the difference could be caused by use of pulse current to heat the sample powder. We assumed that the pulse current generates a highly heated region at the interfaces of the $\mathrm{Al}$ particles, which leads to the break up of the oxide layer. In order to verify this assumption, the heating mechanism of the PCP sintering process of $\mathrm{Al}$ powder was examined.

A mold, punches and sample powder play the role of a 

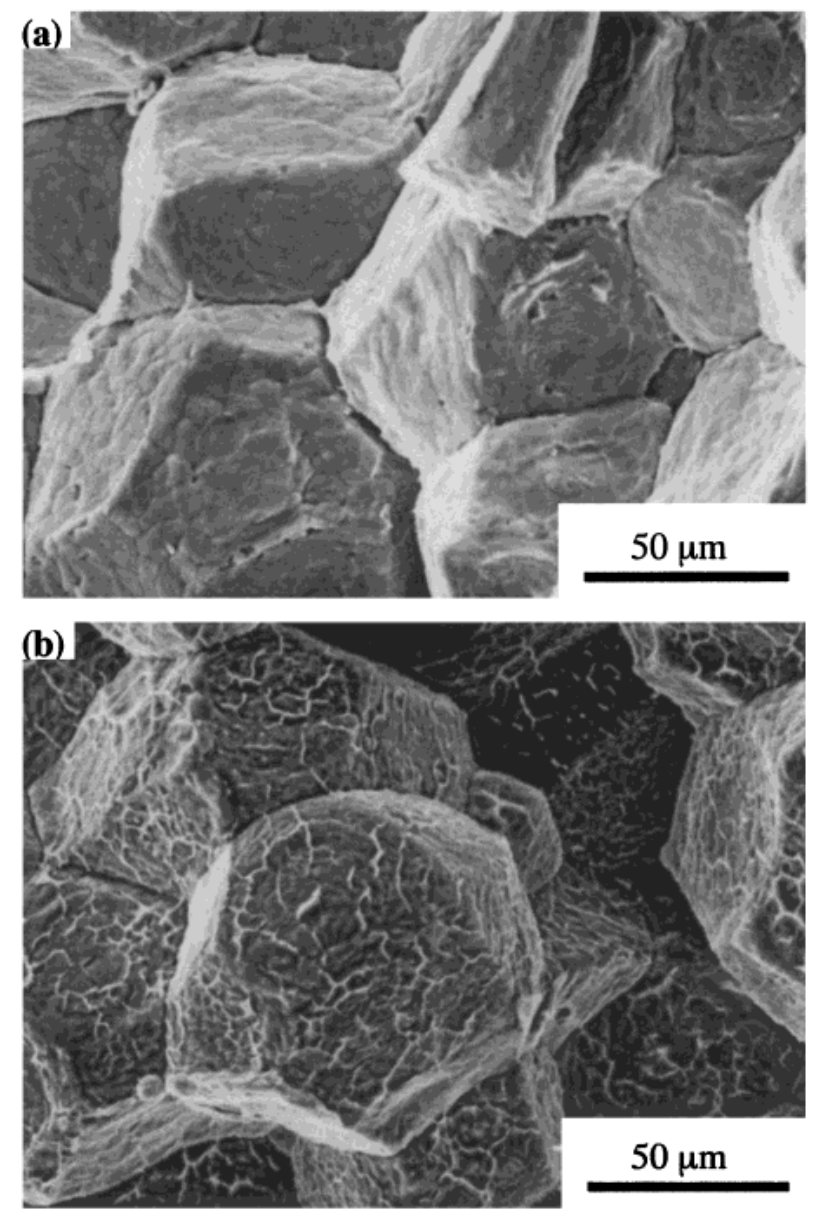

Fig. 9 Fractured surface of the sintered compact after a tensile test. These specimen were sintered by (a) the hot pressing method and (b) the pulse current pressure sintering method at $873 \mathrm{~K}$ for $300 \mathrm{~s}$ under a load of $40 \mathrm{MPa}$.

heater in the PCP sintering process. According to literature, ${ }^{9-13)}$ when isolation like ceramics were sintered by the PCP process, the temperature of the mold was higher than that of the specimen. When electric conductor like metals were sintered, the temperature of the specimen was higher than that of the mold. That is to say, no heat transfer occurred to the conductive sample powder from the mold during heating, so the sample powder is heated by only the Joule heat of the powder itself. By examining the heat mass generated at each $\mathrm{Al}$ particle, the Joule heat generated at the interface of the particles can be quantified.

Figure 12(a), is a case that a sphere particle of radius $r$, was deformed by pressure, $P$, at a temperature, $T$. Total heat quantity, $Q_{\mathrm{tot}}$, generated by Joule heating of the particle is expressed by eq. (3).

$$
Q_{\mathrm{tot}}=I^{2} R_{\mathrm{tot}}
$$

$I$ : current passing through an $\mathrm{Al}$ particle

$R_{\text {tot }}$ : total electric resistance of an Al particle

The resistance of a particle, $R_{\mathrm{tot}}$ is expressed as a series circuit of resistance of a particle body, $R_{\mathrm{m}}$, and a contact resistance, $R_{\mathrm{c}}$, by eq. (4)

$$
R_{\mathrm{tot}}=R_{\mathrm{m}}+R_{\mathrm{c}}
$$

$R_{\mathrm{m}}$ is expressed by eq. $(5)^{21)}$
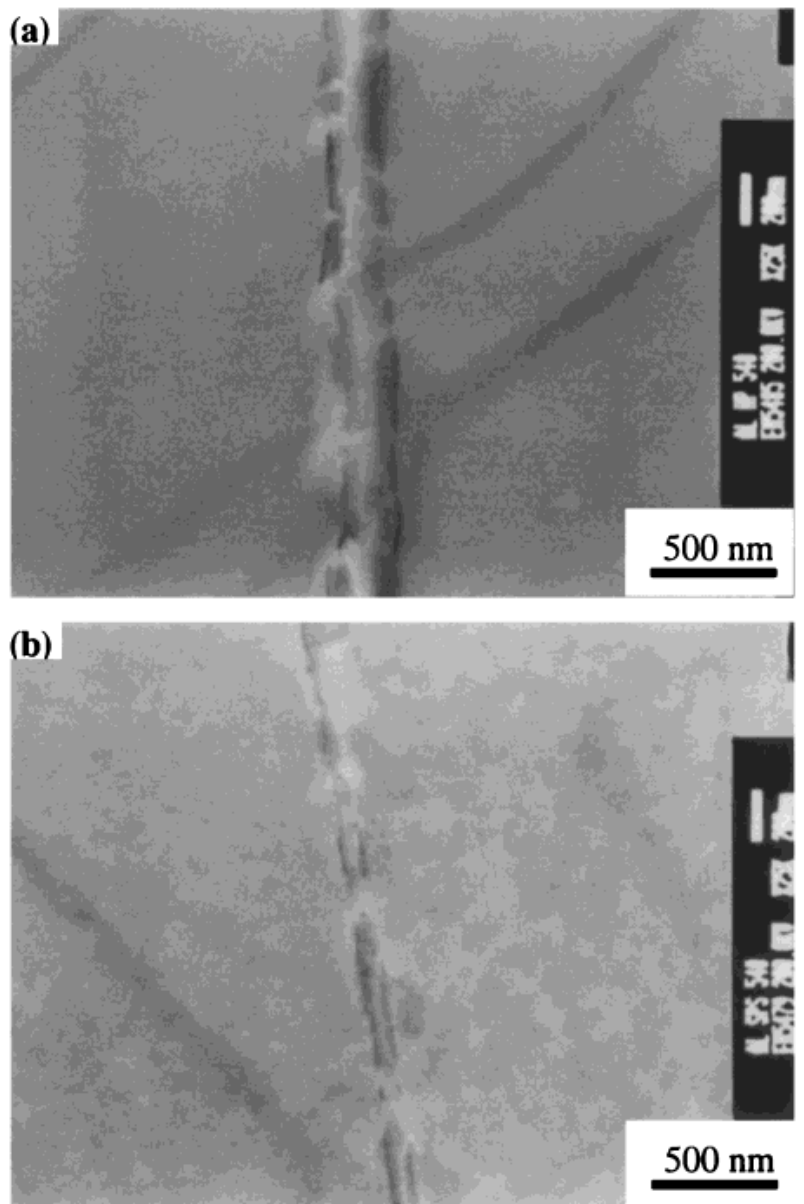

Fig. 10 The oxide layer of the specimen which was sintered by (a) the hot pressing method and (b) the pulsed current pressure sintering method at $813 \mathrm{~K}$ for $600 \mathrm{~s}$ under a load of $40 \mathrm{MPa}$.

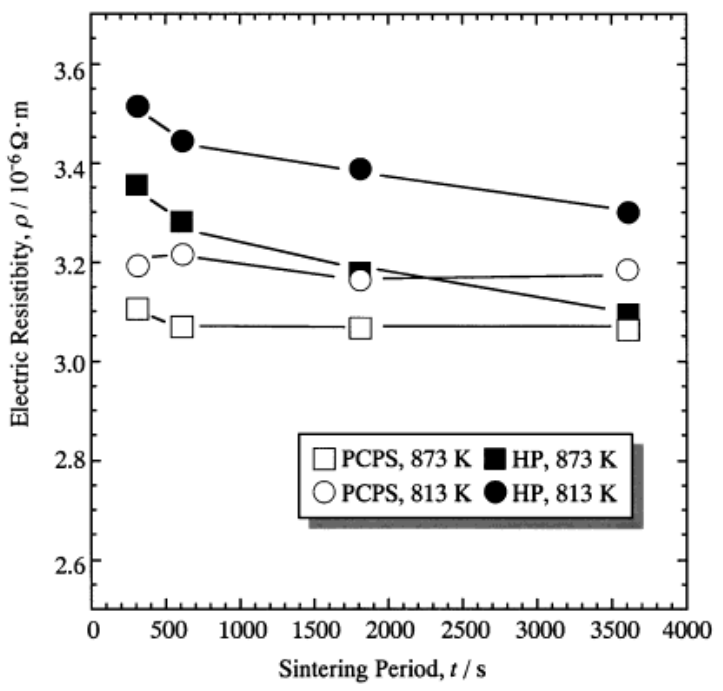

Fig. 11 Electric resistivity of gas atomized Al powder compacts sintered by the pulse current pressure sintering and the hot pressing method.

$$
R_{\mathrm{m}}=-\mu_{\mathrm{Al}} \int_{-A}^{A}\left(1 / S_{\mathrm{x}}\right) \mathrm{d} x
$$

Here, $A=\left(r^{2}-r_{0}^{2}\right)^{1 / 2}$

$\mu_{\mathrm{Al}}$ : relative resistance of $\mathrm{Al}$ at $T(\mathrm{~K})$ 


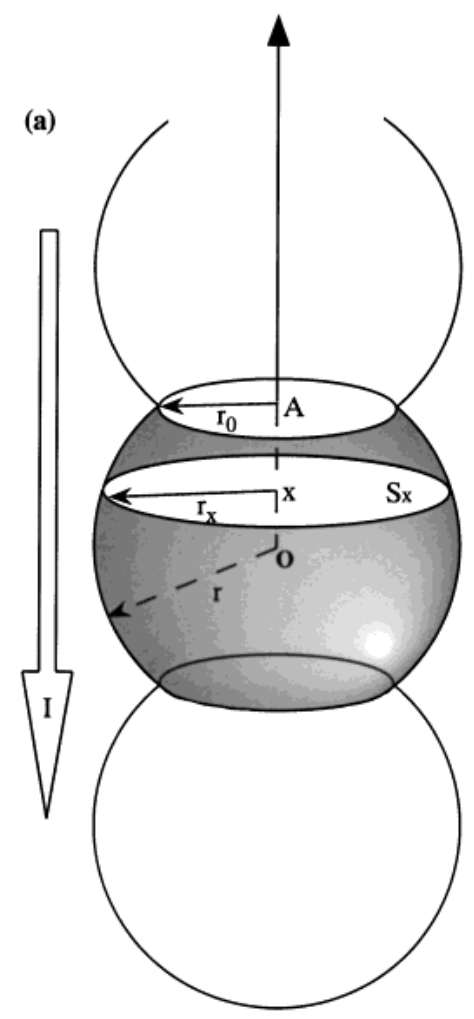

(b)

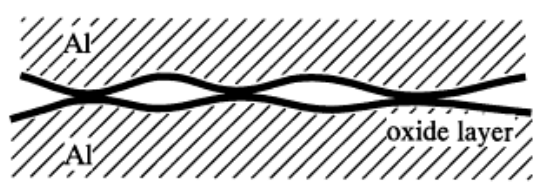

(c)

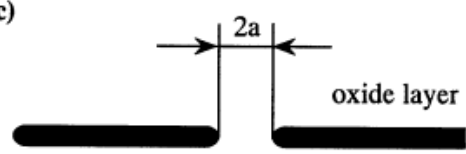

(d)

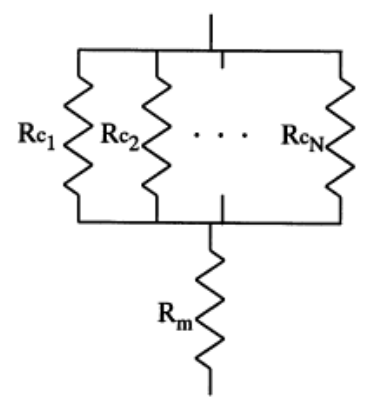

Fig. 12 Schematic illustration of aluminum particles which play the role of a resistive element during the pulse current pressure sintering process.

$S_{\mathrm{x}}$ : cross-sectional area of Al particle at $x$ apart from the center

$r_{0}$ : radius of contact area

Hence,

$$
R_{\mathrm{m}}=-\mu_{\mathrm{Al}} / \pi r \cdot \log |(A-r) /(A+r)|
$$

In the early stage of PCP sintering, the sample particles do not contact each other at every point of the interface, but they contact in spots like Fig. 12(b). In this case, the electric resistance of the interface is expressed by the concentration resistance, $R_{\mathrm{c}}$. Concentration resistance occurs when the electric current is narrowed down as shown in Fig. 12(c). This is expressed by eq. (7). ${ }^{22)}$

$$
R_{\mathrm{c}}=\mu_{\mathrm{Al}} / 2 a
$$

$a$ : radius of contact point

Contact points are formed a lot at the interface. They are connected in parallel, and the resistance of the interface is expressed by,

$$
R_{\mathrm{c}}=\mu_{\mathrm{Al}} / 2 N a
$$

$N$ : number of contact points

Thus, the Al particle can be treated as an assembly of the resistances shown in Fig. 12(d). The whole resistance which is necessary for Joule heat of an Al particle is described by eq. (9). This is rearranged by substituting (6), (8) into (4).

$$
R_{\mathrm{tot}}=\mu_{\mathrm{Al}} / 2 N a-\mu_{\mathrm{Al}} / \pi r \cdot \log |(A-r) /(A+r)|
$$

On the other hand, we argue about the heat quantity necessary for heating of an $\mathrm{Al}$ particle. The temperature increase per one pulse of current, $\Delta T$, is expressed by eq. (10).

$$
\Delta T=v_{\mathrm{t}} t_{0}
$$

$v_{\mathrm{t}}$ : heating ratio

$t_{0}$ : conducting period of a pulse current

In order to increase the temperature $\Delta T$, a heat quantity of $Q$ is needed.

$$
Q=c_{\mathrm{Al}} V \rho_{\mathrm{Al}} \Delta T=\left(4 \pi r^{3} / 3\right) c_{\mathrm{Al}} \rho_{\mathrm{Al}} v_{\mathrm{t}} t_{0}
$$

$c_{\mathrm{Al}}$ : specific heat of the $\mathrm{Al}$

$V$ : volume of an Al particle

$\rho_{\mathrm{Al}}$ : density of the Al

Assuming that this heat was generated by only the Joule heat of a particle, we can estimate the current passing through a particle per one pulse current from eqs. (3) and (11). In this experiment, the sintering conditions are $t_{0}=40 \mathrm{~ms}^{23}$ ) and $v_{\mathrm{t}}=0.3 \mathrm{~K} / \mathrm{s}$, so the temperature increase per one pulse of current can be estimated as $0.012 \mathrm{~K}$ from eq. (10). Heat quantity at $570 \mathrm{~K}$, to increase an $\mathrm{Al}$ particle $0.012 \mathrm{~K}$, is obtained to be $1.75 \times 10^{-8} \mathrm{~J}$ from (11). We can estimate the Joule heat generation at the contact point using the value of current passing through a contact point calculated from the value of current passing through and $\mathrm{Al}$ particle from the eq. (3). In the meantime, eq. (8) of the contact resistance works out when we assume that the surface of an Al particle is clean without an oxide layer. As the strong oxide layer exists in nature, this equation stands only at the region of the metal-metal direct contact point where the oxide layer is broken down. The electric current is considered to pass through these cracks in the PCP sintering process. We can estimate the heat generation, $Q$, at a contact point of the crack of the oxide layer 


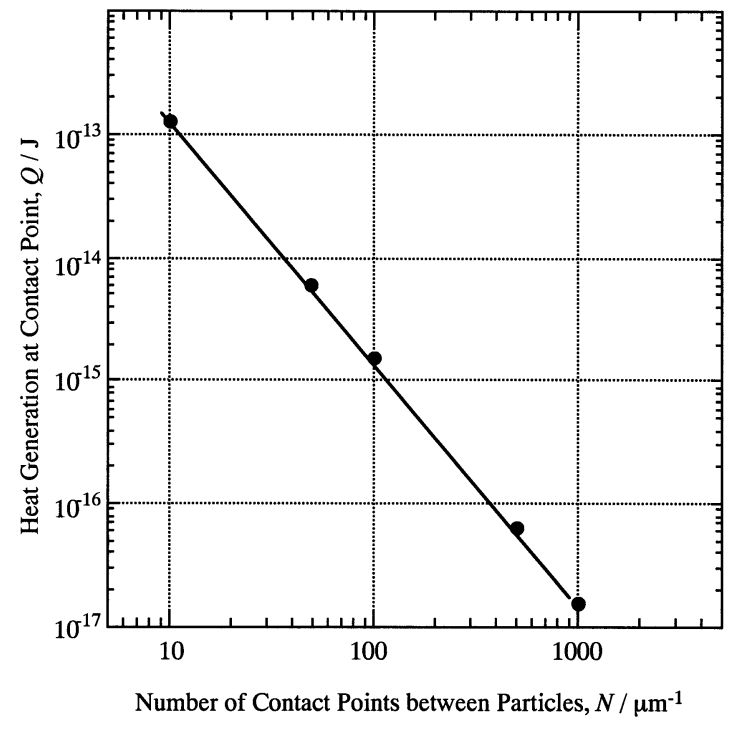

Fig. 13 Heat generation at contact points between aluminum powders versus the number of contact points.

using eq. (8). Judging from the TEM photo of the HP specimen (Fig. 10), the size of the cracks made by axial pressure is about $10 \mathrm{~nm}$ in diameter. It means that $2 a=10 \mathrm{~nm}$ in eq. (8). Assuming that the number of metal-metal contact points are, $N=10,50,100,500$ and 1000, the calculated value, $Q$ is plotted on a logarithmic graph against the value $N$ in Fig. 13. The heat generation greatly increases as the contact points derease.

The number of cracks in the oxide layer estimated from the TEM photo of the HP specimen is about $50 \sim 100 / \mu \mathrm{m}^{2}$. Heat generation at the crack of oxide is calculated to be $5 \times 10^{-15} \sim 1.5 \times 10^{-15} \mathrm{~J}$ from Fig. 13. Assuming that all of this generated heat goes to the temperature increase of the contact point and the size of the contact point ( = crack of oxide layer (thickness is about $5 \mathrm{~nm}^{24)}$ )) is $10 \mathrm{~nm}$ in diameter and $10 \mathrm{~nm}$ in thikness, then, the temperature increase at the crack region is calculated from eq. (11) to be about $700 \sim 2700 \mathrm{~K}$. Since the average temperature of the powder, $T$ is $570 \mathrm{~K}$, the temperature of the crack region is at least $T+\Delta T=1270 \mathrm{~K}$, which is higher than the melting point of $\mathrm{Al}(933 \mathrm{~K})$. Fluidity and heat expansion of the contact region become greater, so the oxide is considered to be broken up. In the case that the $\Delta T=2700 \mathrm{~K}$, the energy given to this region is enough to break up the oxide layer. Thus, the electric current which flows through the contact region of the $\mathrm{Al}$ particle is supposed to play a great role in the sintering of Al powder.

\section{Conclusion}

Water atomized and gas atomized $\mathrm{Al}$ powder was sintered by pulse current pressure (PCP) sintering and hot press (HP) sintering processes. The microstructure and mechanical properties between these sintering methods were compared to estimate the sintering mechanism of the PCP sintering process. Results obtained are as follows:

(1) Water atomized powder contains a lot of adsorbed water in its oxide layer. Hydrogen gas generated by the reaction of the adsorbed water and the $\mathrm{Al}$ was out gassed in a short time by the PCP sintering process. The PCP sintering process could densify the water atomized $\mathrm{Al}$ powder in a shorter time than the HP sintering process. Although oxide was generated during sintering by the PCP sintering process, the tensile strength was higher than that of HP sintered compact. This is the reason that the oxide layer on irregularly shaped Al particles is easily broken up by shear deformation.

(2) Although gas atomized powder has a clean surface with less adsorbed gas than water atomized powder, the tensile strength of a gas atomized powder compact by PCP and HP sintering processes was lower than that of a water atomized powder compact. The reason is that the oxide layer on the sphere shaped $\mathrm{Al}$ particle is less broken up by shear deformation.

(3) The metal-metal contact of each Al particle in the PCP sintered compact was made at the cracks of the oxide layer. Joule heat generation at the contact region is greatly affected by the number of cracks at this region. The temperature increase of the contact region is roughly estimated to be $700 \sim 2700 \mathrm{~K}$ by one pulse current during the PCP sintering process. Energy provided by pulsed current is supposed to play a great role in the sintering of $\mathrm{Al}$ powder.

\section{Acknowledgements}

The authors wish to acknowledge the help and advice on TEM observation of the oxide layer received from Prof. Ikeuchi of the Joining and Welding Research Institute of Osaka University. This research was partially supported by the Ministry of Education, Science and Culture, Grant-in-Aid for Scientific Research B-2, 13555203, 2001.

\section{REFERENCES}

1) T. Nagae, M. Nose, M. Yokota and S. Saji: Proc. Int. Symposium on Designing, Processing and Properties of Advanced Engeneering Materials, (JSPS AEM 156 Commitee, Japan, 1997) pp. 625-630.

2) T. Nagae, S. Saji, T. Yanagimoto, M. Nose and M. Yokota: Mater. Trans., JIM 41 (2000) 457-460.

3) T. Takida, M. Mabuchi, M. Nakamura, T. Igarashi, Y. Doi and T. Nagae: Metall. Mater. Trans. A 31A (2000) 715-721.

4) S. Tomida, T. Nagae and K. Nakata: Preprints of the National Meeting of JWS 65 (1999) 586-587.

5) A. Oomori, M. Hasegawa, M. Tokita and M. Sonoda: Proc. of the Meeting of High Temp. Soc. (1994) p. 26.

6) M. Tokita: J. Soc. Powder Technol. Jpn. 30 (1993) 790-804.

7) M. Yokota, T. Nagae and M. Nose: Proc. of the 1998 Powder Metallurgy World Congress \& Exhibition 2 (1998) 284-289.

8) K. Matsugi, T. Hatayama and O. Yanagisawa: J. Japan Inst. Metals 59 (1995) 740-745.

9) M. Nanko, T. Maruyama and T. Tomino: J. Japan Inst. Metals 63 (1999) 917-923.

10) S. Sumi, Y. Mizutani and M. Kometani: J. Japan Powder Powder Metal. 45 (1998) 153-157.

11) O. Oohashi, T. Yoshioka, I. Nitta, H. Hasegawa and S. Sugii: J. Japan Inst. Metals 63 (1999) 983-988.

12) T. Nagae, M. Yokota and M. Nose: J. Jpn. Powder Powder Metal. 44 (1997) 945-950.

13) Y. Makino, M. Kamai, T. Ohmae and S. Miyake: Proc. of the International Symposium on Microwave, Plasma and Thermochemical Processing of Advanced Materials, (1997) pp. 77-81.

14) K. Ozaki, K. Kobayashi, T. Nishio, A. Matsumoto and A. Sugiyama: J. Jpn. Powder Powder Metal. 47 (2000) 293-297.

15) K. Nishimoto, K. Saida, R. Tsuduki and O. Katsuyama: Preprints of the National Meeting of JWS 66 (2000) 196-197. 
16) H. Kimura and S. Kobayashi: J. Japan Inst. Metals 58 (1994) 201-207.

17) M. Nose, T. Nagae and M. Yokota: J. Jpn. Powder Powder Metal. 45 (1998) 670-674.

18) Y.-W. Kim, W. M. Griffith and F. H. Froes: J. of Metals, Aug. (1985) pp. 27-33.

19) Japan Inst. Metals: Kinzoku Databook, Maruzen, 3 (1993).

20) R. M. German: Powder Metallurgy Science 2nd edition, (Uchida rokakuho, 1996) pp. 252-255.
21) Inst. of Electrical Engineers of Japan: Electrical Engineering Handbook (1978) p. 64.

22) T. Enjo, K. Ikeuchi and N. Akikawa: J. of JWS 51 (1982) 272-279.

23) M. Tokita, M. Kawahara and M. Sonoda: Proc. 1998 Spring Meeting of Japan Powder, Powder Metall. 81 (1998) 135.

24) ASM Handbook vol. 7, Powder Metal Technology and Applications pp. 155-156. 